\title{
Fatal Side Effect of Treprostinil - Hypoglycemia: A Case Report
}

\section{Dongling Luo, Caojin Zhang* and Yigao Huang}

Guangdong Provincial Cardiovascular Institute, Guangdong General Hospital, Guangdong Academy of Medical Sciences, China

*Corresponding author: Caojin Zhang, Guangdong Provincial Cardiovascular Institute, Guangdong General Hospital, Guangdong Academy of Medical Sciences, China

Treprostinil is generally safe and efficacious prostacyclin analog that is recommended for patients with NYHA class III/IV pulmonary hypertension. The reported side effects of standard dosing of treprostinil include fatigue, facial flush, headache, chest pain, dyspnea, right ventricular heart failure and pallor. Other side effects include abdominal cramping, diarrhea, jaw pain, edema, vasodilation and nausea [1]. Hypoglycemia as a side effect of treprostinil is extremely rare. We report the first case of severe hypoglycemia after using treprostinil in a patient with severe idiopathic pulmonary arterial hypertension.

\section{Case History}

A 27-year-old woman presented to our department complaining of progressive dyspnea for the past ten months, especially during exercise. She also complained of abdominal distension, swelling of the lower extremi- ties and increasing weight loss. She was diagnosed with idiopathic pulmonary arterial hypertension 4 years ago by the right heart catheterization, which demonstrated severe pulmonary hypertension with a mean pulmonary artery pressure of $60 \mathrm{mmHg}$. The patient was started on furosemide $20 \mathrm{mg}$ once a day, warfarin $1.5 \mathrm{mg}$ per night, tadalafil $10 \mathrm{mg}$ twice a day and bosentan 125 $\mathrm{mg}$ twice a day since then and her exercise tolerance improved but relapsed occasionally. She had no history of other medical problems. Vital signs on admission included a temperature of $36.7^{\circ} \mathrm{C}$, blood pressure of $84 / 59 \mathrm{mmHg}$, pulse rate of $96 / \mathrm{min}$, respiratory rate of $20 /$ min. Physical examination revealed clear lungs without crackles or rales, and her cardiac examination revealed a thrill at the fourth intercostals space on the left side of the sternal body. Cardiac auscultation revealed a 4/6 systolic murmur. Abdominal examination revealed a distended abdomen with a positive shifting dullness.

Table 1: Lab tests after admission.

\begin{tabular}{|c|c|c|c|c|c|c|}
\hline & $\begin{array}{l}\text { Glu } \\
(3.89-6.11) \\
\text { mmol/L }\end{array}$ & $\begin{array}{l}\mathrm{K}^{+} \\
(3.5-5.5) \\
\mathrm{mmol} / \mathrm{L}\end{array}$ & $\begin{array}{l}\mathrm{Na}^{+} \\
(137-147) \\
\mathrm{mmol} / \mathrm{L}\end{array}$ & $\begin{array}{l}\mathrm{Cl}^{-} \\
(99-110) \\
\mathrm{mmol} / \mathrm{L}\end{array}$ & $\begin{array}{l}\mathrm{Ca}^{2+} \\
(2.08-2.6) \\
\mathrm{mmol} / \mathrm{L}\end{array}$ & $\begin{array}{l}\mathrm{Mg}^{2+} \\
(0.7-1.1) \\
\mathrm{mmol} / \mathrm{L}\end{array}$ \\
\hline 10-23 19:47 & 6.78 & $2.84 \downarrow$ & $127.3 \downarrow$ & $91.1 \downarrow$ & 2.11 & - \\
\hline 10-24 09:04 & 4.18 & 4.39 & $129.1 \downarrow$ & $95.2 \downarrow$ & 2.14 & 0.89 \\
\hline $10-25 \quad 21: 51$ & 4.33 & 3.94 & $129.8 \downarrow$ & $96.7 \downarrow$ & 2.1 & - \\
\hline \multicolumn{7}{|c|}{$10-2519: 00$ treprostinil $1.25 \mathrm{ng} / \mathrm{Kg} / \mathrm{min}$} \\
\hline $10-28 \quad 14: 25$ & 5.65 & $2.61 \downarrow$ & $133.8 \downarrow$ & $98.7 \downarrow$ & 2.11 & - \\
\hline \multicolumn{7}{|c|}{ 10-28 19:00 treprostinil $2.7 \mathrm{ng} / \mathrm{Kg} / \mathrm{min}$} \\
\hline 10-29 02:39 & 5.52 & 4.36 & $133.1 \downarrow$ & 99 & $2.02 \downarrow$ & 0.82 \\
\hline 10-29 03:21 & 4.90 & 4.6 & $134 \downarrow$ & - & - & - \\
\hline 10-29 10:20 & $1.50 \downarrow$ & \multicolumn{5}{|l|}{ Coma } \\
\hline 10-29 15:28 & 17.07 & 5.63 & 135.5 & 101 & 2 & - \\
\hline
\end{tabular}

Glu: Blood Glucose; K+: Potassium; Na+: Sodium; Cl: Chloride; $\mathrm{Ca}^{2+}$ : Calcium; $\mathrm{Mg}^{2+}$ : Magnesium; $\downarrow$ : The value is lower than the normal range.

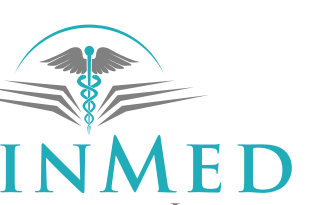

INTERNATIONAL LIBRARY
Citation: Luo D, Zhang C, Huang Y (2018) Fatal Side Effect of Treprostinil - Hypoglycemia: A Case Report. Clin Med Rev Case Rep 5:234. doi.org/10.23937/2378-3656/1410234

Accepted: September 10, 2018: Published: September 12, 2018

Copyright: (c) 2018 Luo D, et al. This is an open-access article distributed under the terms of the Creative Commons Attribution License, which permits unrestricted use, distribution, and reproduction in any medium, provided the original author and source are credited. 


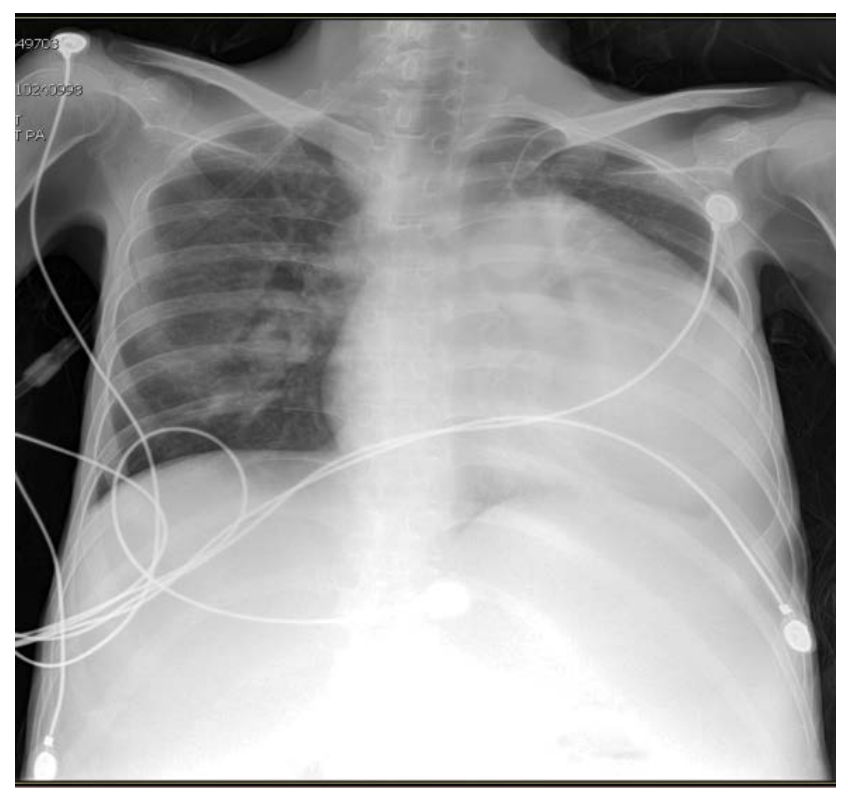

Figure 1: Perivascular haziness, interstitial edema and enlarged cardiac silhouette.

Neurological examination was unremarkable. There was $2+$ pitting edema of the lower extremities. Laboratory tests showed a serum glucose level of $6.78 \mathrm{mmol} / \mathrm{l}$, NT-proBNP level of $7619 \mathrm{pg} / \mathrm{ml}$ and a normal liver and renal function. Measurement of the electrolytes were shown in Table 1. X-ray of the chest revealed perivascular haziness, interstitial edema, and an enlarged cardiac silhouette (Figure 1). Transthoracic echocardiogram confirmed severe right heart failure with no inspiratory collapse of the inferior vena cava and right heart enlargement. The TAPSE was $10.6 \mathrm{mmHg}$. The estimated systolic pulmonary arterial pressure was $97 \mathrm{mmHg}$ and there's little fluid in the pericardial space.

The patient was continued on furosemide, spironolactone, warfarin, bosentan and tadanafil and under careful monitoring of her electrolytes after admission. Blood pressure was maintained by dopamine with a dosage of $3.8 \mathrm{ug} / \mathrm{kg} / \mathrm{min}$.

Two days after admission (25 $5^{\text {th }}$ October 2014), the patient developed progressive dyspnea and infusion of treprostinil was on with a dosage of $1.25 \mathrm{ng} / \mathrm{kg} / \mathrm{min}$. On the fifth hospitalization day (28 ${ }^{\text {th }}$ October 2014), the intravenous treprostinil was uptitrated to the doses of $2.7 \mathrm{ng} / \mathrm{kg} / \mathrm{min}$ and her symptom of dyspnea improved. During the process of uptitration, her serum potassium decreased to a level of $2.51 \mathrm{mmol} / \mathrm{l}$. After potassium administration, her serum potassium increased to a level of $4.36 \mathrm{mmol} / \mathrm{l}$ and maintained above $4.0 \mathrm{mmol} / \mathrm{l}$, as shown in Table 1.

Six hours later, the patient felt progressive dyspnea and nausea. She vomited once, throwing out $10 \mathrm{ml}$ water-like vomitus. Vital signs included a BP of 120/67 $\mathrm{mmHg}, \mathrm{HR}$ of $108 / \mathrm{m}$ and oxygen saturation of $80 \%$. Symptoms improved with oxygen supplementation. However, the patient lost her consciousness eight hours later with bilateral eye-staring, though recovered a few seconds later. Unfortunately, she lost her consciousness soon after and gradually developed into coma. Vital signs included blood pressure of $88 / 58 \mathrm{mmHg}, \mathrm{HR} 97 \mathrm{~b}-$ pm, oxygen saturation of $91 \%$. Neurologic examination revealed symmetric pupils with the size of $3 \mathrm{~mm}$ bilaterally and reactive to light. Repeat blood sugar levels had decreased from $4.9 \mathrm{mmol} / \mathrm{l}\left(3: 21,29^{\text {th }}\right.$ October 2014) to $1.5 \mathrm{mmol} / \mathrm{l}\left(10: 20,29^{\text {th }}\right.$ October 2014).

Though she regained her consciousness after glucose infusion, she became agitated and died the next day.

\section{Discussion}

Treprostinil is a tricyclic benzindene analog of prostacyclin and metabolized by CYP2C8 in the liver [2-4]. Common side effects include fatigue, facial flush, headache, chest pain, dyspnea, right ventricular heart failure and pallor. Till now, hypoglycemia as a side effect of treprostinil has not been reported yet.

In this case, our patient was started on treprostinil after exacerbation of dyspnea. Though her symptoms improved after this add-on therapy, she developed severe hypoglycemia after uptitration. We thus believed that hypoglycemia could be a rare but fatal side effect of treprostinil.

Theoretically, hypoglycemia develops when glucose efflux out of the circulation exceeds glucose influx into the circulation. Therefore, it's easy to develop hypoglycemia if glucose consumption exceeds glucose intake. In this case, there could be several reasons that caused her hypoglycemia after using treprostinil. Firstly, treprostinil can be metabolized into five metabolites. One of the metabolites is the glucuronoconjugate of treprostinil, which tends to increase glucose consumption during metabolism [2-4]. Secondly, as it's known, treprostinil are direct and potent vasodilation of pulmonary and systemic arterial beds through increased level of intracellular cAMP. As a result, vasodilation helps to decrease the afterload of the left and right ventricle and thus improved the stroke volume and cardiac output. With the increase of cardiac output and relief of organ congestion (especially the liver and intestine), the perfusion and metabolism of the end organs improve, thus causing increased glucose consumption. Last but not least, our patient developed hypopotassium during the course of using treprostinil. It is believed that glucose consumption would be increased in the state of hypopotassium due to higher concentration difference between cellular membranes. This could further risk her for developing hypoglycemia. If, together with insufficient glucose intake, hypoglycemia would easily take place. As is shown in our case, though her symptoms improved after treprostinil uptitration, she developed severe hypoglycemia 14 hours later.

To the best of our knowledge, this is the first published case of severe hypoglycemia caused by trepros- 
tinil used in pulmonary hypertension patient. Despite the frequent use of treprostinil, awareness about the potential hypoglycemic effect is poor. Therefore, we recommend only clinicians experienced in the diagnosis, treatment, and follow-up of primary arterial hypertension should use treprostinil.

In conclusion, hypoglycemia associated with the use of treprostinil is an uncommon occurrence but can be fatal and often responds easily with glucose supplementation. Increased awareness can prevent significant mortality and mobidity associated with this rare but life-threatening side effect of this widely used drug in the field of pulmonary hypertension.

\section{Disclosure}

None.

\section{References}

1. Treprostinil (treprostinil sodium) injection. Drug insert, United therapeutics Corp.

2. Steffen RP, de la Meta M (1991) The effects of 15AU81, a chemically stable prostacyclin analog, on the cardiovascular and renin-angiotensin systems of anesthetized dogs. Prostaglandins Leukot Essent Fatty Acids 43: 277-286.

3. McNulty MJ, Sailstad JM, Steffen RP (1993) The pharmacokinetics and pharmacodynamics of prostacyclin analog 15AU81 in anesthetized beagle dog. Prostaglandins Leukot Essent Fatty Acids 48: 159-166.

4. RemodulinTM (2002) Treprostinil sodium. Investigators Brochure, United Therapeutics Corporation, USA. 